\title{
Feasibility of High Pressure Freezing With Freeze Substitution After Long-Term Storage in Chemical Fixatives
}

\author{
CHANTELLE VENTER,${ }^{1}$ CHRISTIAAN FREDERICK VAN DER MERWE, ${ }^{2}$ HESTER MAGDALENA OBERHOLZER, ${ }^{1}$ * \\ MEGAN JEAN BESTER, ${ }^{1}$ AND HELENA TAUTE ${ }^{1}$ \\ ${ }^{1}$ Department of Anatomy, Faculty of Health Sciences, University of Pretoria, South Africa \\ ${ }^{2}$ Laboratory for Microscopy and Microanalysis, Faculty of Natural and Agricultural Sciences, University of Pretoria, South Africa
}

KEY WORDS high pressure freezing; transmission electron microscopy; hepatocytes; sample storage

\begin{abstract}
Fixation of biological samples is an important process especially related to histo-logical and ultrastructural studies. Chemical fixation was the primary method of fixing tissue for transmission electron microscopy for many years, as it provides adequate preservation of the morphology of cells and organelles. High pressure freezing (HPF) and freeze substitution (FS) is a newer alternative method that rapidly freezes non-cryoprotected samples that are then slowly heated in the FS medium, allowing penetration of the tissue to insure adequate fixation. This study addresses several issues related to tissue preservation for electron microscopy. Using mice liver tissue as model the difference between samples fixed chemically or with HPF immediately after excision, or stored before chemical or HPF fixation were tested with specific focus on the nuclear membrane. Findings are that immediate HPF is the method of choice compared to chemical fixation. Of the chemical fixatives, immediate fixation with $2.5 \%$ glutaraldehyde (GA)/form-aldehyde (FA) is the best in preserving membrane morphology, 2.5\% GA can be used as alternative for stored and then chemically processed samples, with $10 \%$ formalin being suitable as a storage medium only if followed by HPF fixation. Overall, storage leads to lower ultrastructural preservation, but HPF with FS can minimize these artifacts relative to other processing protocols.
\end{abstract}

\section{INTRODUCTION}

With the advances in microscopy, the preservation of tissue has become important in understanding the tissue structure and function. The purpose of chemical tissue fixation is to preserve tissue with minimal alterations to the native state (DiStefano, 2008). When it came to achieving the goal of minimal alterations to the native state, two types of preservation methods came to existence namely chemical fixation protocols and the rapid freezing of samples. The reason for the universal use of chemical fixation can be attributed to the adequate preservation of many cell components and the clarity of structural detail viewed with Transmission Electron Microscopy (Hayat, 1989). With chemical fixation, the commonly used fixatives in most laboratories are glutaraldehyde (GA) and paraformaldehyde. The reason for the use of aldehydes is due to the formation of protein, carbohydrate, and nucleic acid crosslinks. These crosslinks form a mesh-work that secures the tissue molecules in place, in a near native state (DiStefano, 2008). Paraformaldehyde is a white powder that is the polymer of formalin and was the main fixative to use until Karnovsky proposed that GA and paraformaldehyde should be used together to increase the preservation of the specimens (Ellis, 2009). Paraformaldehyde's reaction with proteins and peptides is efficient, as it produces protein-bridges between the neighbouring protein chains (Coetzee and Loots, 1993). GA is seen as one of the best chemical fix- atives for preservation of detailed structure. However high concentrations of GA can denature the proteins in the sample and especially in immunohistochemistry analysis this tissue cannot be used. The penetration rate of the fixative is also significant, as inadequate penetration in a given time will render the tissue unusable. Thus formaldehyde (FA) will penetrate the sample faster than GA, as FA is a mono-aldehyde and thus a smaller molecule whereas GA is a di-aldehyde, bigger and less penetrating. The greater crosslinking ability creates a greater barrier to penetration into the tissue, GA/FA is a compromise between these.

The second method developed for specimen preservation is high pressure freezing (HPF). The idea for HPF already existed in 1968 with Moore and Riehle who first proposed the idea, but unfortunately since then the impact on biomedical research has been comparatively small (Studer et al,, 2001). According to Studer et al. (2001) only about 100 papers have been published that dealt with HPF as a method for studying biological structures since it was first described. The reason for the low use of HPF may be due to the high cost of purchasing and operating a high pressure

\footnotetext{
*Correspondence to: H. M. Oberholzer, Department of Anatomy, Faculty of Health Sciences, University of Pretoria, Private Bag x323, ARCADIA 0007, South Africa. E-mail: nanette.oberholzer@up.ac.za
} 
freezer, together with the additional equipment needed for processing the samples at low temperatures (Kan, 2010). HPF is a method that can vitrify noncryoprotected samples thicker than $50 \mu \mathrm{m}$, without visible ice crystal damage when viewed with an electron microscope. What makes HPF so unique is the fact that the samples are physically immobilized in milliseconds (Studer et al., 2001). Freeze substitution (FS) entails that an organic solvent such as acetone, ethanol, or methanol substitutes the vitrified water in the cells, at a temperature of $-90^{\circ} \mathrm{C}$. Substitution of water at these low temperatures minimizes the collapse and shrinkage of cells that normally occurs at room temperature (McDonald, 1999). Osmium and GA are added to the FS medium as fixation agents, and the former for contrast enhancement of lipids in the membranes. When you combine the FS medium and fixative, the fixative penetrates the cells while the cells are immobilized. When the temperature is increased, the fixative has already penetrated the cell, where chemical crosslinking takes place and fixation of the cells occurs (McDonald, 1999).

Another tissue preservation method used in the medical sciences is embalming fluid. Embalming fluid is typically used to preserve cadavers for the purpose of dissection. The embalming fluid consists of a group of chemicals which serves to ensure preservation of the body and prevent deterioration and structural disturbances as well as contamination with microbes. Often the need exists for the use of cadaver tissue for histological and ultrastructural studies and therefore embalming fluid was included in this study to determine the possibility of using cadaver tissue in morphological studies by investigating the organelles and structures within the hepatocyte.

Therefore, in this article the effect of storage of mice liver tissue in chemical fixatives before further processing (chemical or HPF) was tested to address the question of whether HPF at a later stage can still yield high quality tissue preservation for morphological and ultrastructural studies, in cases where the tissue cannot be processed immediately. The nuclear membrane is the structure selected to demonstrate the effect of the different sample preparation methods. Although only the nuclear membranes are depicted in this article, the membranes of the hepatocytes, mitochondria, and rough endoplasmic reticulum (rER) were also investigated in order to determine the best processing method. The nuclear envelope consists of a double lipid bilayer which encloses the nucleus (Coetzee et al., 2003; Hetzer and Wente, 2009). In between these two layers an intramembranous space that is proximately $20-30 \mathrm{~nm}$ wide is found. The outer membrane, that is adjacent to the cytosol of the cell, is in some areas continuous with the rER (Coetzee et al., 2003). On the outer membrane surface ribosomes are also present. The inner membrane is located adjacent to the chromatin of the nucleus (Coetzee et al., 2003; Hetzer and Wente, 2009). In some places in the nuclear envelope, nuclear pores can be found. The nuclear pores are octagonal with a diameter of between 30 and $100 \mathrm{~nm}$ (Coetzee et al., 2003).

\section{MATERIALS AND METHODS}

Liver tissue from ten control $\mathrm{BALB} / \mathrm{c}$ mice was obtained from the University of Pretoria Biomedical
Research Centre (UPBRC) [Ethical clearance number H18/09 NECSA]. Liver tissue was cut into $1 \mathrm{~mm}^{3}$ samples and fixed separately. The samples were fixed in either $2.5 \% \mathrm{GA} / \mathrm{FA} ; 2.5 \% \mathrm{GA} ; 10 \%$ formalin or embalming fluid. The remaining liver sections were processed with $\mathrm{HPF}$ and FS. The stored samples were left in the fixatives for three weeks and then either further chemically processed or high pressure frozen. An ultramicrotome and JEOL $2100 \mathrm{~F}$ transmission electron microscope were respectively used to section and view the samples.

\section{Fixatives Used}

2.5\% Glutaraldehyde/Formaldehyde. Tissue samples were fixed in $2.5 \% \mathrm{GA} / \mathrm{FA}$ ( $1 \mathrm{~mL}$ of $25 \% \mathrm{GA}, 1$ $\mathrm{mL}$ of $25 \% \mathrm{FA}$ (freshly prepared from paraformaldehyde), $5 \mathrm{~mL} \mathrm{PO}_{4}$ buffer $\left.(0.15 \mathrm{M}), 3 \mathrm{~mL} \mathrm{ddH}_{2} \mathrm{O}\right)$ for $1 \mathrm{~h}$, rinsed three times in $0.075 \mathrm{M}$ sodium phosphate buffer $(\mathrm{pH}=7.4)$ for $15 \mathrm{~min}$ each before they were placed in secondary fixative, $1 \%$ osmium tetroxide solution, for $1 \mathrm{~h}$. Following fixation, the tissues were rinsed again as described above. The samples were dehydrated in a graded $\mathrm{EtOH}-\mathrm{H}_{2} \mathrm{O}$ series consisting of $30 \%, 50 \%, 70 \%$, $90 \%$, and three changes of $100 \%$ ethanol. The samples were embedded in epoxy resin and ultra-thin sections (70-100 nm) were cut with a diamond knife using an ultramicrotome (Reichert Ultracut E). Samples were then contrasted with $2 \%$ aqueous uranyl acetate for 5 min followed by 2 min of contrasting with lead citrate, after which samples were allowed to dry for a few minutes before examination with the JEOL Transmission Electron microscope (JEM 2100F).

2.5\% Glutaraldehyde. Tissue samples were fixed in $2.5 \% \mathrm{GA}\left(1 \mathrm{~mL} 25 \% \mathrm{GA}, 5 \mathrm{~mL} \mathrm{PO}_{4}\right.$ buffer, $4 \mathrm{~mL}$ $\mathrm{ddH}_{2} \mathrm{O}$ ) for $1 \mathrm{~h}$ after which the same sample preparation methods were followed as described above.

10\% Formalin. Tissue samples were fixed in $10 \%$ formalin $(1 \mathrm{~mL}$ commercial $40 \%$ formalin, $1 \mathrm{~mL}$ $\mathrm{ddH}_{2} \mathrm{O}, 2 \mathrm{~mL} \mathrm{PO}_{4}$ buffer) for $1 \mathrm{~h}$ after which the same sample preparation methods were followed as described above.

Embalming Fluid. Embalming Fluid with the following formula was obtained from the Anatomy Department at the University of Pretoria: Industrial methylated spirits (45 L), phenol $85 \%$ diluted in water (10 L), mono-ethylene glycol (40 L), formalin (5 L), thymol $(50 \mathrm{~g})$ and is made up to $100 \mathrm{~L}$. Tissue samples were fixed in embalming fluid for $1 \mathrm{~h}$ after which the same sample preparation methods were followed as described above.

High Pressure Freezing. Mice liver tissue samples were cut using a scalpel to a thickness of $200 \mu \mathrm{m}$ and trimmed with specimen punch to $1 \mathrm{~mm}$ in diameter. The samples were placed into a flat membrane carrier, loaded into the HPF (Leica EM Pact 2) and fast frozen (Sosinsky et al., 2008).

Freeze Substitution. After HPF, the liver samples were transferred to the FS (Leica EM AFS 2) machine. FS was done with $0.5 \%$ osmium tetroxide in 99\% acetone solution (Walther and Ziegler, 2002). The FS schedule used was: $8 \mathrm{~h}$ at $-90^{\circ} \mathrm{C}$, warming from $-90^{\circ} \mathrm{C}$ to $-70^{\circ} \mathrm{C}$ for $6 \mathrm{~h}$, left at $-70^{\circ} \mathrm{C}$ for $10 \mathrm{~h}$, warming from $-70^{\circ} \mathrm{C}$ to $-60^{\circ} \mathrm{C}$ over a $4 \mathrm{~h}$ period and finally warming from $-60^{\circ} \mathrm{C}$ to $0^{\circ} \mathrm{C}$ over a $20 \mathrm{~h}$ period. The samples were rinsed once with pure acetone while at 

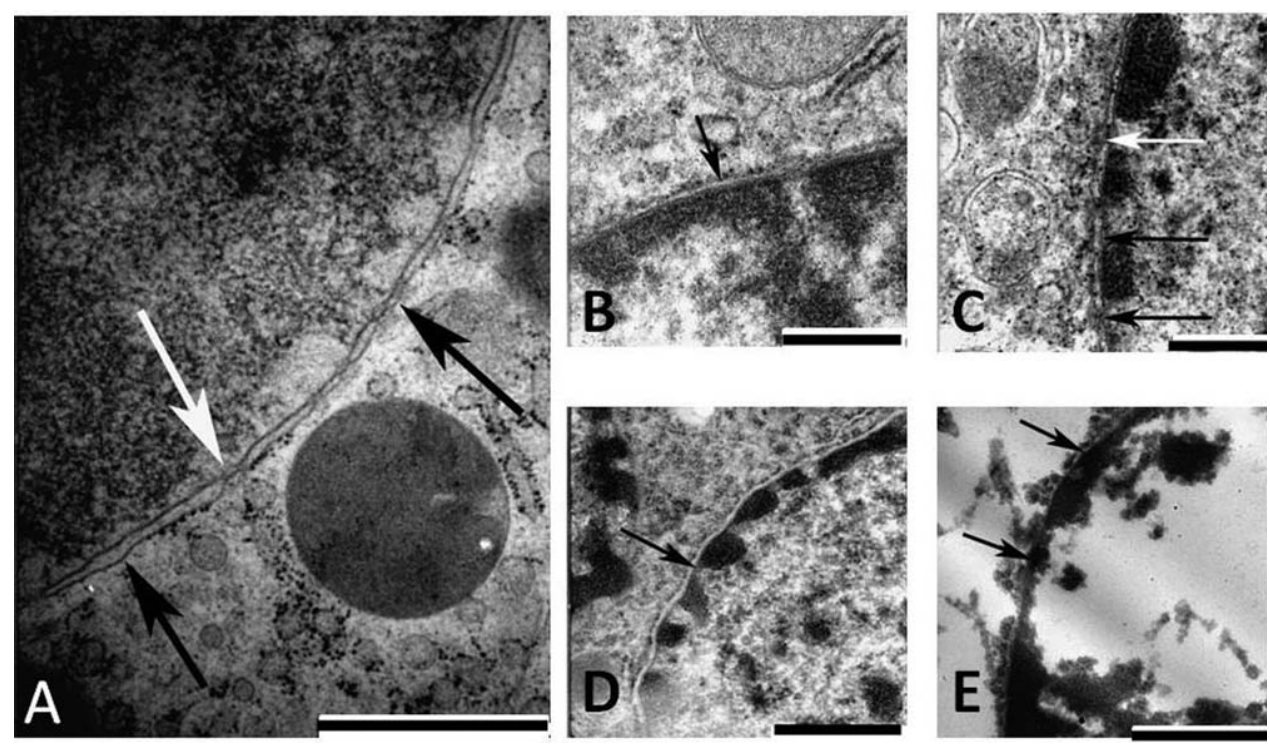

Fig. 1. TEM micrographs of immediately processed liver tissue. Nuclear membrane of hepatocyte of HPF samples (A); $2.5 \%$ GA/FA (B); $2.5 \%$ GA (C); $10 \%$ formalin (D), and embalming fluid (E). The nuclear membrane is indicated by the black arrows and white arrows indicate nuclear pores. (Scale bars $A=11 \mathrm{~m} ; \mathrm{B}=500 \mathrm{~nm} ; \mathrm{C}=500$ $\mathrm{nm} ; \mathrm{D}=11 \mathrm{~m} ; \mathrm{E}=11 \mathrm{~m})$. $-15^{\circ} \mathrm{C}$. The samples were rinsed three times with $100 \%$ acetone, with 5 min intervals (Sosinsky et al., 2008) and embedded in epoxy resin. Ultra-thin sections (70-100 $\mathrm{nm}$ ) were made with an ultramicrotome using a diamond knife, contrasted with uranyl acetate for $5 \mathrm{~min}$ followed by $2 \mathrm{~min}$ of lead citrate and viewed with the JEOL Transmission Electron microscope.

Storage Time. Tissue samples were also placed in the different chemical fixatives mentioned above and left for a period of three weeks, where after these were either fast frozen by HPF or further chemically processed as described above.

Evaluation of Samples. Micrographs of the membranes of the nuclei, mitochondria, and rER of hepatocytes were evaluated for any structural differences. The immediately processed HPF samples were used as reference to compare the other processing protocols with.

\section{RESULTS}

In Figure 1 the TEM micrographs of immediately processed liver tissue are shown. Figure $1 \mathrm{~A}$ is representative of the liver tissue processed immediately with HPF after dissection. When comparing the samples in Figure 1, the HPF sample (Fig. 1A) has a clearly visible inner and outer nuclear membrane and the intramembranous space is clearly visible. Nuclear pores can be seen (white arrow) and ribosomes (black particles) are also visible on the nuclear envelope. In the $2.5 \%$ GA/FA sample (Fig. 1B), the intramembranous space is clearly visible, with somewhat unclear inner and outer membranes. In the samples processed with $2.5 \%$ GA (Fig. 1C), the membrane is unclear and undulated as is the case for the samples fixed in $10 \%$ formalin (Fig. 1D) as well. The liver tissue fixed in embalming fluid can be seen and in Figure $1 \mathrm{E}$ the inner membrane is still visible but the outer membrane is completely destroyed.
In Figure 2, TEM micrographs of liver tissue processed after a 3 week storage period in the same chemical fixatives as described above, and subsequently processed with HPF or chemical fixation are shown. Figure $2 \mathrm{~A}$ is representative of the liver tissue stored in $2.5 \% \mathrm{GA} / \mathrm{FA}$ and then processed with HPF where the double membrane of the nucleus is still visible but unclear (black arrows) compared to Figure 1A where the tissue was processed immediately. In Figure $2 \mathrm{~B}$ the outer membrane (black arrows) is destroyed, but the intramembranous space can still be identified. When comparing Figure 2C and D which represents the samples stored in $2.5 \%$ GA and then processed with HPF (Fig. 2C) or chemically processed (Fig. 2D), it can be seen that the membranes are not clearly visible in Figure 2C and in Figure 2D the outer membrane is undulated and appears uneven around the nucleus as indicated by the black arrows. In the samples stored in $10 \%$ formalin and then processed with HPF (Fig. 2E), the nuclear membrane is unclear but the intramembranous space can still be recognized, (black arrows) whereas the samples stored in $10 \%$ formalin and then chemically processed (Fig. 2F) revealed an undulated nuclear membrane that is unclear. Figures $2 \mathrm{G}$ and $2 \mathrm{H}$ are representative of the liver tissue samples stored in embalming fluid before being processed with HPF (Fig. 2G) or chemically processed (Fig. 2H). In Figure 2G the outer membrane is destroyed (black arrows), but with the intramembranous space still visible. In Figure $2 \mathrm{H}$ the outer membrane is completely destroyed, where the inner membrane is recognizable but fairly disrupted (black arrows).

\section{DISCUSSION}

Sample preparation of biological tissue plays a vital role in obtaining high quality ultrastructural preservation; therefore it is important to compare different sample preparation techniques to determine the 

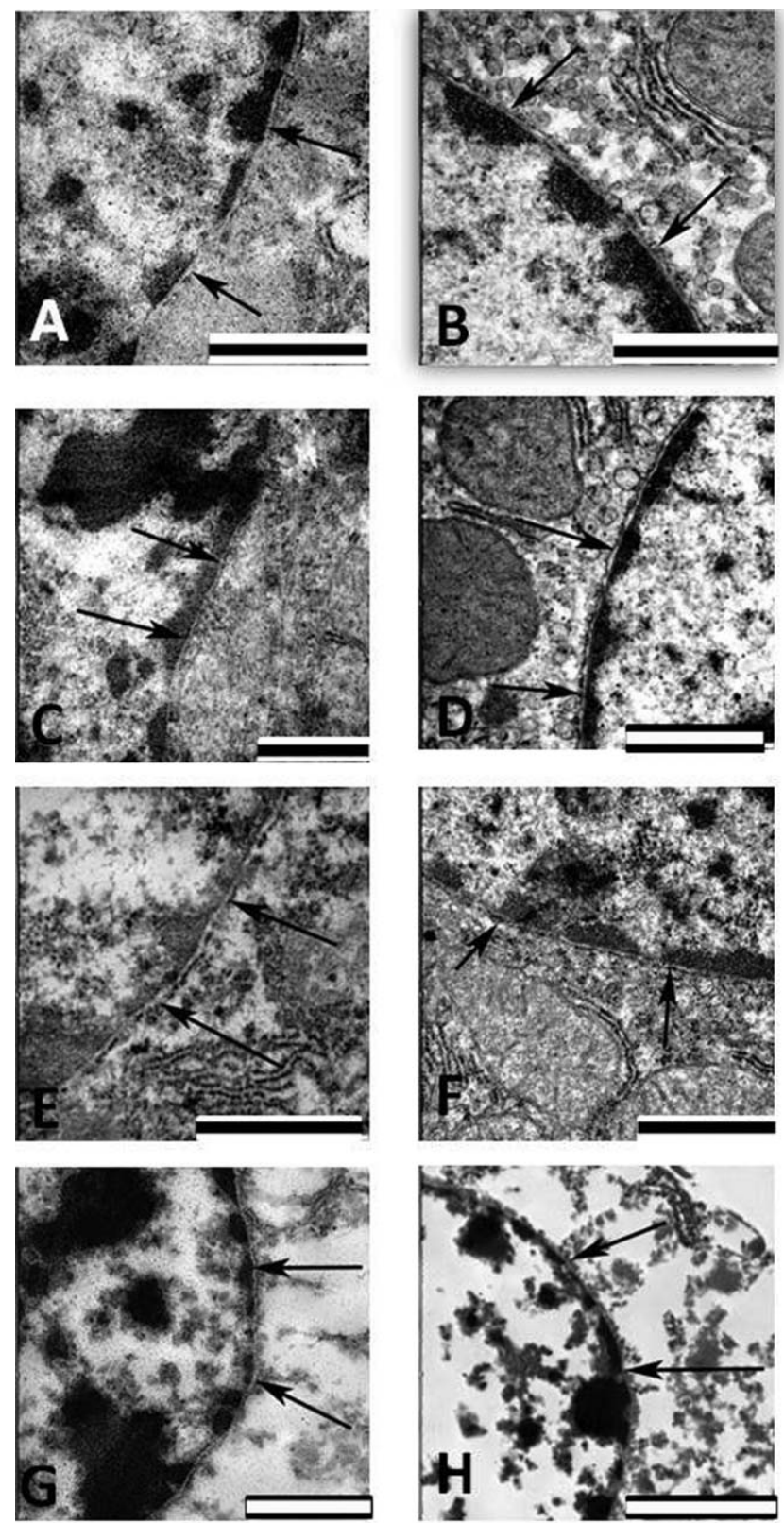

Fig. 2. TEM micrographs of liver tissue processed after a 3-week storage period. Nuclear membrane of hepatocyte of samples stored in $2.5 \% \mathrm{GA} / \mathrm{FA}$ and then HPF (A) and chemically processed (B); stored in $2.5 \%$ GA and then HPF (C) and chemically processed (D); stored in $10 \%$ formalin and then HPF (E) and chemically processed $(\mathbf{F})$; stored in embalming fluid and then HPF $(\mathbf{G})$ and chemically processed $(\mathbf{H})$ (Black arrows indicate nuclear membranes) (Scale bars: $\mathrm{A}-\mathrm{G}=13 \mathrm{~m}$; $\mathrm{H}=23 \mathrm{~m})$

optimal technique for a specific application. In the current study, we investigated the possibility of storing mice liver tissue in chemical fixatives before further processing, whether via chemical or HPF fixation to determine whether HPF at a later stage can still yield high quality tissue preservation for morphological and ultrastructural studies, especially in cases where immediate tissue processing is not possible.

In 1996, Royer and Kinnamon compared HPF and FS with chemical fixation of catfish barbel taste buds
(Royer and Kinnamon, 1996). These authors found an increase in smoothness of the plasma membrane of organelles; a more evenly distributed cytoplasmic matrix as well as a distinct perinuclear space when using HPF. This was also seen in the current study where the nuclear membranes of the HPF samples were clearer, with the individual components of the membrane more distinguishable. With the analysis of the other structures used in this study, that included the hepatocytes, mitochondria, and rER membranes, the same results were obtained as seen in that of the nuclear membrane. The membranes of the high pressure frozen samples were more distinct than the results obtained from the chemically fixed, stored, and chemically processed and stored and high pressure frozen samples. These results further confirmed the results obtained from analysis of the nuclear membranes.

The results obtained in this study clearly indicate that the storage of samples in $10 \%$ formalin before further processing with HPF for ultrastructural studies is feasible. For storage in chemical fixatives for a period of time before continuation with the chemical preparation process, $2.5 \%$ GA showed promising results. Overall the stored and then HPF samples yielded better results compared to the stored and then chemically processed samples. HPF of samples stored in fixatives prevents structural damage associated with chemical preparation after a storage period. In the case where HPF-FS is not available and immediate chemical fixation is the method of choice, it was found that $2.5 \%$ GA/FA yields the best results compared to the other chemical fixatives used in this study.

\section{CONCLUSION}

Tissue preservation is a vital step in preparing samples for TEM to obtain high quality micrographs for morphological and ultrastructural studies. HPF is currently the optimum method to use, as it promises enhanced morphological results. Often, immediate processing of samples by HPF may not always be possible and chemical fixation is the only alternative. Immediate HPF is the method of choice compared to immediate chemical fixation. Of the chemical fixatives, immediate fixation in $2.5 \% \mathrm{GA} / \mathrm{FA}$ best preserves the membrane morphology, 2.5\% GA can be used as alternative for stored and then chemically processed samples, with $10 \%$ formalin that can be used as the storage fixative when samples are prepared with HPF after a storage period. Storage in fixatives compromises sample quality and images obtained for morphological and ultrastructural studies. Therefore it can be concluded that HPF and FS result in optimum quality micrographs for ultrastructural studies even after prolonged storage in fixatives.

\section{REFERENCES}

Coetzee HL, Loots GP. 1993. Histologiese ligen elektronmikroskopie. South Africa: Department of Anatomy, University of Pretoria. pp. 4-6.

Coetzee HL, Loots GP, Meiring JH. 2003. Human histology, 1st ed. Pretoria, South Africa: Van Schaik Publishers. pp. 29-30.

DiStefano AK. 2008. Cryofixation and chemical fixation comparison based on extracellular matrix preservation. ProQuest. Basingstoke, Hampshire. 4-5.

Ellis EA. 2009. A fast, simple, and safe way to prepare paraformaldehyde solutions. Micros Today 17:48-49. 
Hayat MA. 1989. Principles and techniques of electron microscopy: Biological applications, 3rd ed. Macmillan press scientific and medical, Macmillan Press. Basingstoke, Hampshire. p 4.

Hetzer MW, Wente SR. 2009. Border control at the nucleus: Biogenesis and organization of the nuclear membrane and pore complexes. Dev Cell 17:606-616.

Kan B-H. 2010. Chapter 12-Electron microscopy and high pressure freezing of Arabidopsis. Methods Cell Biol 96:259-283.

McDonald K. 1999. High pressure freezing for preservation of high resolution structures and antigenicity of immunolabeling, methods in molecular biology. In: Hajibagheri MAN, editor. Electron microscopy methods and protocols. London: Springer. pp. 77-97.
Royer SM, Kinnamon JC.1996. Comparison of high pressure freezing/ freeze substitution and chemical fixation of catfish barbel taste buds. Microsc Res Tech 35:385-412.

Sosinsky GE, Crum J, Jones YZ, Lanman J, Smarr B, Terada M, Martone ME, Deerinck TJ, Johnson JE, Ellisman MH. 2008. The combination of chemical fixation procedures with high pressure freezing and freeze substitution preserves highly labile tissue ultrastructure for electron tomography applications. J Struct Biol 161:359-371.

Studer D, Graber W, Al-amound A, Eggli P. 2001. A new approach for cryofixation by high pressure freezing. J Microsc 203:285-294.

Walther P, Ziegler A. 2002. Freeze substitution of high-pressure frozen samples: The visibility of biological membranes is improved when the substitution medium contains water. J Microsc 208:3-10. 